\title{
Tax Avoidance, Corporate Governance and Corporate Innovation
}

\author{
Kong Jianhua \\ Chengdu Textile College, Chengdu 611731
}

Key words: Corporate Tax Avoidance; Corporate Governance; Corporate Innovation

\begin{abstract}
In the background of implementation the strategy of innovation-driven development, this paper investigates the impact of corporate tax avoidance on corporate innovation. Using applications of invention patents as a proxy of corporate innovation, we find that tax avoidance significantly reduce the firm's innovation ability, which supports the agency cost hypothesis in corporate tax avoidance; and the negative relation between tax avoidance and corporate innovation will decrease with the improvement of corporate governance. This paper will contribute to the literature on economic consequences of corporate tax avoidance and influence factors of corporate innovation. It also has the important implication for our understanding for how to promote the corporate innovation by tax avoidance.
\end{abstract}

\section{Introduction}

The party's eighteen major reports clearly put forward the implementation of innovation driven development strategy to adapt to the new normal state of China's economic development. As the main part of market economy, the promotion of independent innovation capability is an important guarantee for the realization of these strategic objectives[1].

Based on the sample of 2003-2013 years' Listed Companies in Shanghai and Shenzhen stock markets, this paper discusses the above issues by referring to Jiang Xuanyu's method and measuring the number of patent applications by measuring the innovation of enterprises in A. The results show that tax avoidance is negatively related to enterprise innovation, which supports the hypothesis of agency theory of tax avoidance. At the same time, the negative relationship between the two firms decreases with the improvement of corporate governance. The contribution of this paper is mainly embodied in the following three points. (1) the existing literature mainly discusses the influencing factors of corporate tax avoidance, and lacks the research on its economic consequences. Following the stock crash risk, earnings quality, compensation contract effectiveness, enterprise value, the tax avoidance behavior and the important strategic investment enterprise innovation together, to enrich the research of the economic consequences of corporate tax avoidance behavior. (2) the existing literature mainly from its abundant cash flow, improve the level of working capital management discussed the effect of endogenous financing management of enterprise innovation, this article from the perspective of tax planning, enrich the research results on the factors affect innovation. (3) this paper finds that corporate governance can significantly inhibit the negative relationship between tax avoidance and enterprise innovation, and also has important implications on how to curb agency problems in tax avoidance and promote enterprise innovation[2].

\section{Theoretical analysis and research hypothesis}

The influence of tax avoidance on enterprise innovation is uncertain. Whether or not tax avoidance promotes or inhibits enterprise innovation depends on which of the above factors dominates. It is a topic awaiting empirical study. Thus, a set of competing hypotheses is proposed in this paper[3].

H1a: the higher the level of tax avoidance, the higher the level of innovation, the positive correlation between the two.

H1b: the higher the level of tax avoidance, the lower the level of innovation, the negative 
correlation between the two.

As pointed out in the analysis of hypothesis 1, the impact of tax avoidance on enterprise innovation is uncertain, mainly because of the existence of serious conflicts of interest between managers' motives for tax avoidance. Within the enterprise and outside, a series of corporate governance mechanism is a strong guarantee to reduce the adverse selection and moral hazard of managers and to coordinate the conflict of interests between shareholders and managers. Existing studies also find that effective corporate governance mechanisms can mitigate agency problems in managers' tax avoidance. For example, Kim et al. (2011) and Jiang Xuanyu (2013) found that corporate governance environment can reduce the positive relationship between corporate tax avoidance activities and stock crash risk; Wang Jing et al (2014) found that corporate governance high levels of tax evasion can weaken the negative relationship with the value of companies. According to a similar logic, along with raising the level of corporate governance, can be expected to corporate tax avoidance activities will be more in line with the interests of the shareholders, to create more tax revenue to support enterprise innovation. Therefore, the hypothesis of this paper is put forward. 2:

H2: a high level of corporate governance can reduce (increase) the negative (positive) relationship between tax avoidance and corporate innovation.

\section{Research design}

This article selects 2003-2013 Shanghai and Shenzhen two listed A shares of listed companies as the research object, the number of patent applications and types are derived from the State Intellectual Property Office "China patent full-text database"; institutional ownership data from the WIND database; other data from the CSMAR database. Considering the relevant database, institutional ownership and analyst forecast data, the earliest year was 2003, so the research period started in 2003[3].

In the choice of specific samples in this paper as follows: (1) with reference to the existing literature (Jiang Xuanyu, 2013; Chen Deqiu, 2016), excluding the actual tax rate is greater than 1 or less than 0 , and pre tax profit is less than or equal to 0 of the sample; (2) excluding the financial sector in the sample; (3) excluding the research required the sample data is incomplete. Based on the above criteria, 13708 firm annual observations are finally obtained. At the same time, Winsorize processing is performed at the $1 \%$ and $99 \%$ levels of the continuous variable in the model to reduce the interference of the data outliers on the results.

This paper tests the hypothesis 1 and hypothesis 2 by model (1) and (2) respectively. Considering the dependent variable, the number of patent applications can not be negative, and it is a trailing variable with a lower limit of 0 . Therefore, the Tobit model is used to estimate[4].

$$
\begin{aligned}
\operatorname{Ln}(1+P A T)_{i, t+1}= & \alpha+\beta_{1} \times \mathrm{TA}_{i, t}+\gamma \times{\text { Control } \text { Variables }_{i, t}+\varepsilon_{i, t}}_{\operatorname{Ln}(1+P A T)_{i, t+1}=} \\
& \alpha+\beta_{1} \times \mathrm{TA}_{i, t}+\beta_{2} \times \mathrm{TA}_{i, t} \times \mathrm{HCGI}_{i, t}+\beta_{3} \times H C G I_{i, t}+ \\
& \gamma \times \text { Control Variables }_{i, t}+\varepsilon_{i, t}
\end{aligned}
$$

Referring to Jiang Xuanyu (2016) research, this paper uses the number of patent applications for PAT to measure enterprise innovation and processes it by logarithm.

Chen Deqiu as reference (2016) study, the avoidance of the corporate tax from the following two aspects: (1) to measure the degree of tax accounting differences between BTD and BTD=[(pre tax accounting profit and income tax expense and deferred tax expense) / nominal income tax rate / total assets; (2) the nominal income tax rate and the actual income tax rate difference DIFR, DIFR= - nominal income tax (income tax expenses deferred tax expense) / total profit tax. The greater the value of BTD and DIFR, the higher the degree of tax avoidance.

This paper measures the level of corporate governance through the following two methods. First, from Bai et al (2005), Liu Boyan and Han Liyan (2010) study, with second to tenth shareholders square, and the proportion of the first shareholder, issuing $\mathrm{B}$ shares or $\mathrm{H}$ shares, management shareholding ratio, the proportion of independent directors and institutional investors, 
analysts tracking the natural logarithm of the number of, whether to hire the top eight accounting firms, general manager and chairman of the board is two positions, whether state-owned enterprises 10 variables, using principal component analysis method to construct corporate governance index CGI1[in the first principal component to the first principal component, the load coefficient of these 10 variables were $0.297,-0.263,-0.023,0.518,0.200,0.3600 .262,0.345,0.137$ and -0.446 . ] the greater the CGI1, the higher the corporate governance level.

Second, refer to the methods of Xu and so on (2016), construct the corporate governance index CGI2 as follows. First of all, the above 10 indicators are divided into two groups, of which first to eighth indicators are one group, which positively reflects the level of corporate governance. The ninth and 10 indicators are a group, which negatively reflects the level of corporate governance. Secondly, each year, each index of each group is sorted in descending order (ascending order), and each index of each company I is obtained. J ranks RANK_CGi, J, t in each year of T. Among them, when an index $\mathrm{J}$ in the year reflects the best level of corporate governance, ranking 1 , and so on. Finally, according to the following corporate structure, corporate governance index CGI2, the greater the CGI2, the higher the level of corporate governance.

After calculating the corporate governance index CGI1 and CGI2, this paper further constructs whether the corporate governance level is higher and the dummy variable HCGI. Specifically, each year, if the company's CGI1 (CGI2) is located above the sample median, HCGI1 (HCGI2) is valued at 1 , otherwise 0 .

According to the literature (Jiang Xuanyu, 2016), the main control variables are as follows: SIZE, the natural logarithm of total assets; Tobin, Q; the ratio of OCTA company operating activities net cash flow to total assets; the ratio of PPETA, net value of fixed assets to total assets of the company; financial leverage of the company's total assets return rate of LEV; ROA; natural logarithm of AGE year; the proportion of the first shareholder and FIRST square and the proportion of managerial ownership; MHOLD; stock turnover rate of TURNOVER years; the enterprise property rights SOE; in addition, also joined the annual industry dummy variables and dummy variables to control year and industry fixed effects.

Table 1 presents descriptive statistical results of the above analysis variables.

Table 1 descriptive statistics of major variables

\begin{tabular}{lcccccc}
\hline $\begin{array}{c}\text { Variable } \\
\text { name }\end{array}$ & $\begin{array}{c}\text { observat } \\
\text { ion } \\
\text { valu } \\
\text { e }\end{array}$ & Mean & $\begin{array}{c}\text { standard } \\
\text { deviati } \\
\text { on }\end{array}$ & P25 & median & P75 \\
\hline Ln(PAT+1) & 13708 & 0.735 & 1.125 & 0 & 0 & 1.386 \\
BTD & 13708 & 0.003 & 0.025 & -0.008 & 0.001 & 0.012 \\
DIFR & 13708 & 0.000 & 0.125 & -0.038 & 0.003 & 0.056 \\
CGI1 & 13708 & 0.000 & 1.379 & -1.008 & -0.252 & 0.770 \\
CGI2 & 13708 & 50 & 9.177 & 43.413 & 49.817 & 56.408 \\
SIZE & 13708 & 21.694 & 1.185 & 20.861 & 21.534 & 22.344 \\
$Q$ & 13708 & 1.757 & 1.033 & 1.140 & 1.396 & 1.941 \\
OCTA & 13708 & 0.052 & 0.079 & 0.010 & 0.051 & 0.098 \\
PPETA & 13708 & 0.264 & 0.181 & 0.123 & 0.230 & 0.379 \\
LEV & 13708 & 0.464 & 0.203 & 0.314 & 0.475 & 0.618 \\
ROA & 13708 & 0.050 & 0.041 & 0.020 & 0.040 & 0.068 \\
AGE & 13708 & 2.029 & 0.682 & 1.609 & 2.197 & 2.565 \\
FIRST & 13708 & 0.379 & 0.157 & 0.253 & 0.361 & 0.499 \\
MHOLD & 13708 & 0.067 & 0.162 & 0 & 0 & 0.002 \\
TURNOVE & 13708 & 5.360 & 3.726 & 2.610 & 4.433 & 7.118 \\
$\quad R$ & 13708 & 0.473 & 0.499 & 0 & 0 & 1 \\
SOE & & & & & & \\
\hline
\end{tabular}




\section{The main empirical results}

It can be found that whether BTD or DIFR is used to measure the degree of tax avoidance TA, the regression coefficients are significantly negative. That is to say, as a whole, the tax avoidance behavior of enterprises inhibits the expansion of innovation activities. This shows that the adverse effects of agency problems in tax avoidance behavior are dominant, which is consistent with the theoretical analysis of H1b. Each year, if the company's BTD (DIFA) is located above the sample median, BTD_D (DIFR_D) is valued at 1 , otherwise 0 . The result remains the same.

Can be found, either at BTD or DIFR to measure the tax avoidance TA, either with HCGI1 or HCGI2 to measure the level of corporate governance HCGI, regression coefficient TA and HCGI were positive, showed that the higher the level of corporate governance agency problems can inhibit the managers in tax evasion in tax avoidance and suppression, adverse effects on the innovation of enterprises that is consistent with the theoretical analysis on the H2.

Although the explanatory variables in this paper are lag first order, to some extent, they help to overcome the endogenous relations among variables, but endogeneity problems still exist. For example, companies with more innovative investment are more likely to get tax breaks. In order to alleviate the interference of endogenous problems to the research conclusions, this paper uses the tax avoidance degree INDTA (INDBTD or INDDIFR) as the instrumental variable, and carries out the two stage regression. Theoretically, if the level of tax avoidance is higher, the company is also more motivated to tax planning. However, the level of tax avoidance at the industry level is difficult to influence the innovation activities at the corporate level. In the two stage regression results: (1) when the explanatory variables were BTD and TA, statistics weak instrumental variables test were 30.196 and 390.966, show that the tool variables and BTD and TA are highly correlated; (2) the two stage model re estimation, BTD and TA on enterprise innovation return coefficient for -19.214 and -2.174, and were significant at 5\% level of confidence, the conclusion of this paper has not changed.

First of all, according to the Tan (2015) method, the natural logarithm of LN by the invention patent and utility model patent applications and the number of PAT1 (PAT1+1) to measure business innovation, the model (1) and (2) return model. The findings remain unchanged.

Secondly, from the innovation investment, that is, the ratio of $\mathrm{R} \& \mathrm{D}$ costs to total assets, RDTA measures enterprise innovation, and then returns to model (1) and model (2). Because the WIND database provides only data for R \& D in 2006 and beyond, the sample size is reduced to 11868.

\section{Conclusions and implications}

Based on the sample of A listed companies in Shanghai and Shenzhen stock markets for 2003-2013 years, this paper empirically tests the relationship between tax avoidance and corporate innovation, and the impact of corporate governance on the relationship between the two parties. The study found that: (1) tax avoidance significantly inhibited the enterprise innovation, agency theory support for tax avoidance, the adverse effects that tax avoidance in the agent problem of enterprise innovation occupies the dominant position; (2) among the two negative relationship with corporate governance level and weakened, show that the proxy the problem of high level of corporate governance can inhibit the managers in tax evasion of tax avoidance and suppression of adverse effects on the innovation of enterprises.

The research conclusion of this paper has certain theoretical and practical significance. In theory, this study enriches the relevant literature on tax avoidance, economic consequences and factors affecting enterprise innovation. In practice, the conclusions of this study are as follows. (1) we should further understand the impact of tax avoidance on enterprises. In the traditional theory, tax planning helps to reduce the cash flow of enterprises and increase the value of enterprises. But the concept of tax avoidance driving decision is not only difficult to bring tax benefit based on the innovation activities of the formation and even will maintain the competitive advantage of enterprises have a negative effect. (2) we should pay more attention to the perfection of corporate 
governance. Help to alleviate the agency problems of tax avoidance activities in raising the level of corporate governance, thus enhancing the management effect of tax planning on endogenous cash flow, better play the role of tax avoidance to support enterprise innovation, to continuously enhance the competitiveness of enterprises, to achieve innovation driven development strategy.

\section{References}

[1] Chen, S., Chen, X., Cheng, Q., Shevlin, T. 2010. Are family firms more tax aggressive than non-family firms [J]. Journal of Financial Economics 95(1): 41-61.

[2] Desai, M. A., Dyck, A., Zingales, L. 2007. Theft and Taxes [J]. Journal of Financial Economics 84(3): 591-623.

[3] Hall, B.H. The Financing of Research and Development [J]. Oxford Review of Economic Policy, 2002, 18(1), 35-51.

[4] Kim, J. -B., Li, Y., Zhang, L. 2011. Corporate Tax Avoidance and Stock Price Crash Risk: Firm-level Analysis [J]. Journal of Financial Economics 100(3): 639-662.

[5] Mills, L. 1998. Book-tax Differences and Internal Revenue Service Adjustments [J]. Journal of Accounting Research 36(2): 343-356. 